\title{
Complementary and Independent Function for Hoxb4 and Bmil in HSC Activity
}

\author{
A. Faubert, $*$ J. Chagraoui, ${ }^{*}$ N. Mayotte, ${ }^{*}$ M. Fréchette, ${ }^{*}$ N.N. Iscove ${ }^{\dagger}$ \\ R.K. Humphries, ${ }^{\ddagger}$ AND G. SAuvageaU $* \$ \rrbracket \mid$ \\ *Laboratory of Molecular Genetics of Hematopoietic Stem Cells, Institute for Research in Immunology \\ and Cancer (IRIC), University of Montréal, Montréal, Québec, Canada H3C 3J7; '†erry Fox Laboratory, \\ British Columbia Cancer Agency, Department of Medicine, University of British Columbia, Vancouver, \\ British Columbia, Canada V5Z $1 \mathrm{LS} ;{ }^{\ddagger}$ The Ontario Cancer Institute, Department of Medical Biophysics, \\ University of Toronto, Toronto, Canada M5G 2M9; ${ }^{\S}$ Department of Medicine, University of Montréal, Montréal, \\ Québec, Canada H3C 3J7; "I Division of Haematology and Leukemia Cell Bank of Québec (BCLQ), \\ Maisonneuve-Rosemont Hospital, Montréal, Québec, Canada H1T 2 M2
}

\begin{abstract}
Determinants regulating short- and long-term repopulating hematopoietic stem cell (STR-HSC and LTR-HSC) self-renewal remain largely uncharacterized. To gain further insights into HSC self-renewal, we investigated possible genetic interactions between two well-recognized regulators of this process: Bmil and Hoxb4. Using complementation and overexpression strategies in mouse HSCs, we document that Bmil is not required for the in vivo expansion of fetal HSCs but is essential for the long-term maintenance of adult HSCs. Importantly, we show that Hoxb4 overexpression induces an expansion of $\mathrm{Bmil}^{-{ }^{-1}}$ STR-HSCs leading to a rescue of their repopulation defect. In contrast to Hoxb4, we also show that Bmil fails to induce HSC expansion ex vivo. Consistent with these results, we report high levels of Angptl3 and Cbx7 in Hoxb4- and Bmil-transduced cells, respectively. Together, these results support the emerging concept that fate and sustainability of this fate are two critical components of self-renewal in adult stem cells such as HSCs.
\end{abstract}

Self-renewal implies the coordination between cell division and fate such that for at least one progeny, cell differentiation, proliferative senescence, and apoptosis are excluded. In contrast to mouse embryonic stem cells that undergo symmetrical self-renewal divisions in response to leukemia inhibitory factor (LIF) and bone morphogenetic protein (BMP) signaling, most adult stem cells have the capacity to undergo two distinct types of self-renewal divisions: symmetrical and asymmetrical (Shen et al. 2002). In the hematopoietic system, HSCs undergo at least two rounds of mobilization that largely overlap with changes in proliferative status: Indeed, most HSCs are in cycle and symmetrically self-renew (thus expand) at a specific time in the mouse fetal liver (FL) and they then switch to a more quiescent program later in the bone marrow environment where the population is maintained for the entire life of the animal (no expansion, but maintenance of the population). Whether this maintenance phase is established by a balance between symmetrical self-renewal and stem cell loss, by asymmetric self-renewal division, or a combination of these processes remains unclear. In adult mice, HSC symmetrical self-renewal divisions can be experimentally triggered (reactivation of an embryonic program?) under specific conditions such as during the early phase following HSC transplantation (Pawliuk et al. 1996; Antonchuk et al. 2001), and this can be dramatically enhanced upon the engineered overexpression of the Hoxb4 transcription factor or other homeobox genes (Sauvageau et al. 1995; Thorsteinsdottir et al. 1999, 2002; Antonchuk et al. 2001, 2002; Krosl et al. 2003; Cellot et al. 2007; Ohta et al. 2007).

Recent studies have documented that at least two different stem cell populations with more or less equal dif- ferentiation potential can be prospectively isolated. These include the long-term repopulating hematopoietic stem cells (LTR-HSCs) that supply hematopoiesis for the life span of the animal and the short-term repopulating HSCs (STR-HSCs) that contribute to repopulation for up to 3 months after transplantation (Morrison et al. 1997; Christensen and Weissman 2001; Wognum et al. 2003). Until recently, however, this property of short-term versus long-term repopulation was limited to phenotypically defined populations, but new studies have validated, at the single-cell level, the concept that the HSC compartment is highly heterogeneous and includes STR-HSCs and LTR-HSCs (Dykstra et al. 2007; N.N. Iscove, pers. comm.). In these studies, single STR-HSCs could provide multilineage reconstitution for up to 3-4 months posttransplantation, whereas LTR-HSCs contributed to lifelong repopulation. This level of blood cell production, estimated at above $10^{12}$ progeny per STR-HSC, argues that these cells can extensively self-renew, thus introducing the notion (of N.N. Iscove) that it is the ability to sustain self-renewal rather than self-renewal itself that distinguishes LTR-HSCs from STR-HSCs.

Together, these data suggest the existence of two mandatory components that define self-renewal (SR) in LTR-HSCs: one that coordinates fate with cell division (referred to as "execution of SR") and one that ensures the sustainability of this execution through cell divisions (referred to as "sustainability of SR"). Several observations suggest that although Hoxb4 overexpression enhances the execution of SR in defined conditions, the Polycomb group (PcG) gene Bmil may be critical for regulating the sustainability of this process. Indeed, by phenotypical analysis, $B m i 1^{-/-}$HSCs are present in normal 
numbers in FL, but they progressively decrease from embryonic to adult life (Park et al. 2003; Iwama et al. 2004). In addition, although Bmil homozygous null HSCs fail to reconstitute myeloablated recipients for periods extending for more than a few weeks, this defect is complemented by the experimental reintroduction of Bmil in these cells, thus indicating the independence on Bmil for the generation of FL LTR-HSCs. Moreover, a single Hoxa9 + Meis1 leukemia-initiating cell that lacks Bmil expression expands sufficiently to induce lethality in mice, but this expansion is nevertheless limited in time (Lessard and Sauvageau 2003; Park et al. 2003; Iwama et al. 2004). Finally, Bmil is not critical for stem cell homing and does not appear to regulate apoptosis (Park et al. 2003; Iwama et al. 2004). With this in mind, we now report a series of experiments suggesting that Bmil ensures the sustainability of SR in LTR-HSCs and, in contrast to Hoxb4, fails to enhance the execution of SR under comparable experimental conditions.

\section{BMI1 IS REQUIRED FOR ACTIVITY OF ADULT HSC}

Bmil homozygous null fetal liver cells (FLCs) were infected using retroviral vectors (Fig. 1a) and manipulated to assess Bmil function on progenitor and stem cell activities (Fig. 1b). Gene transfer efficiencies for all experiments were between $14 \%$ and $100 \%$ (typically between $60 \%$ and $100 \%$ ). As previously reported, progenitor activity is markedly reduced in $\mathrm{Bmil}^{-/-}$FLCs kept in short-term culture (Fig. 1c). These cells also lack in vivo reconstitution ability (Fig. 1d) (Lessard and Sauvageau 2003). Retroviral transduction of Bmil in Bmi1 $1^{-/}$FLCs rescues both their progenitor and in vivo reconstitution activities (Fig. 1c,d). Moreover, complemented $\mathrm{Bmil}^{-/}$cells (referred to hereafter as $B m i 1^{-1}$ Bmil cells) have the capacity to differentiate into myeloid $\left(\mathrm{Gr}-1^{+}\right.$and $\left.\mathrm{CD} 11 \mathrm{~b}^{+}\right)$and lymphoid $\left(\mathrm{CD} 45 \mathrm{R}^{+}\right.$and $\mathrm{CD}^{+}$) lineages in vivo (Fig. 1e), and they can provide hematopoietic reconstitution when transferred into secondary recipients (data not shown). Because hematopoietic reconstitution is observed when wild-type HSCs are transplanted into $\mathrm{Bmil}^{-/}$mice (Park et al. 2003; Iwama et al. 2004), these results support a cell-autonomous dysfunction for Bmil homozygous null HSC.

To further investigate the requirement for Bmil in adult HSC activity, RNA interference (RNAi) studies were conducted using an approach that we previously validated (Chagraoui et al. 2006). shBmil-transduced progenitor cells were significantly compromised in their ex vivo response to hematopoietic growth factors when compared to control cells (Fig. 1f). Interestingly, multipotent progenitors (i.e., CFU-GEMM) were most sensitive to the acute reduction in Bmil levels (Fig. 1g). Consistent with these data, shBmil-transduced cells were impaired in their in vivo reconstitution activity with only one mouse reconstituted in both the myeloid and the lymphoid compartments 16 weeks post-stem-cell transfer (SCT) (Fig. $1 \mathrm{~h}$, right panel, solid dot).

Together with previous reports confirming that $\mathrm{Bmil}^{--}$ HSCs are not impaired in their survival and homing potential (Park et al. 2003; Iwama et al. 2004), these results indi- cate that Bmil is not required for HSC specification but is essential for their long-term maintenance in vivo.

\section{$B_{M I} 1^{-/}$FL HSCS UNDERGO SR DIVISIONS}

Taking into consideration that mouse HSC populations rapidly expand between embryonic days 10 (E10) and 14.5 (E14.5) (Rebel et al. 1996), experiments were designed to test whether Bmil is required for HSC expansion (i.e., symmetrical self-renewal divisions). In these assays, freshly isolated FLCs were infected with a Bmil retrovirus before their transplantation at limiting dilution into lethally irradiated hosts, and stem cell frequencies were evaluated using the CRU (competitive repopulating unit) assay (Szilvassy et al. 1990). Results from these experiments indicated that HSC frequencies (Fig. 1i,j) and absolute numbers (data not shown) are similar in $\mathrm{Bmil}^{-/-}$or $\mathrm{Bmil}^{+/+}$fetal livers, suggesting that although essential for HSC maintenance, Bmil is not required for embryonic HSC expansion and therefore fetal-liverderived HSCs can symmetrically self-renew in the absence of this gene.

\section{BMI1 OVEREXPRESSION DOES NOT INDUCE HSC EXPANSION}

We next investigated whether Bmil overexpression might trigger HSC expansion and regulate Hoxb4 expression levels. For these experiments, bone marrow cells (BMCs) were transduced using control, Hoxb4, Bmil, or both Hoxb4 + Bmil retroviruses (Figs. 1a and 2a). Western blot and quantitative reverse transcriptase-polymerase chain reaction (Q-RT-PCR) analyses of transduced cells showed that levels of Hoxb4 are not affected in Bmiltransduced cells and similarly that $B m i 1$ is not regulated by Hoxb4 (Fig. 2b and data not shown).

When compared to controls, Hoxb4-transduced KLS (c-Kit ${ }^{+}$Lineage ${ }^{-} \mathrm{Sca}-1^{+}$) cells showed a modest expansion during a 7-day culture period (Fig. 2c). In contrast, expansion of Bmil-transduced KLS cells was significantly higher (Fig. 2c). Accordingly, cell cycle distribution studies indicated a greater proportion of KLS cells in S phase in cultures initiated with Bmil-transduced cells than in green fluorescent protein (GFP) control cultures (data not shown). In agreement with previous findings, both Hoxb4 and Bmil significantly enhanced the generation of myeloid progenitors in culture compared to controls (Fig. 2d) (Sauvageau et al. 1995; Iwama et al. 2004).

The effect of Bmil overexpression on in vivo hematopoietic cell reconstitution and ex vivo HSC expansion was evaluated using the CRU assay. In contrast to results obtained within the same experiment with Hoxb4, Bmiloverexpressing LTR-HSCs did not expand ex vivo and reconstituted primary recipients similarly to control cells (Fig. 2e,f). These experiments were also conducted with cells derived from E14.5 FL and likewise, Bmil overexpression had no effect on LTR-HSC expansion (data not shown). Importantly, control and Bmil-transduced HSCs showed similar expansion and differentiation properties, thus indicating that $\mathrm{Bmil}$ overexpression is not detrimental for stem cell activity (Fig. 2f,g). Interestingly, Bmil over- 
a

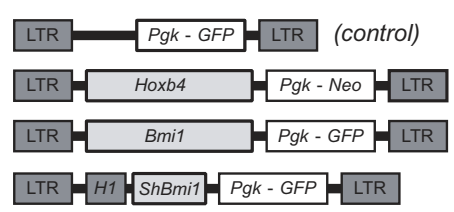

C

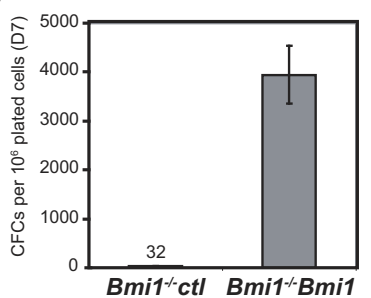

d

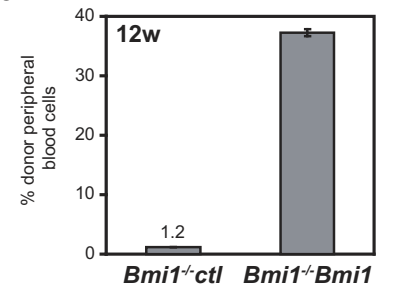

f

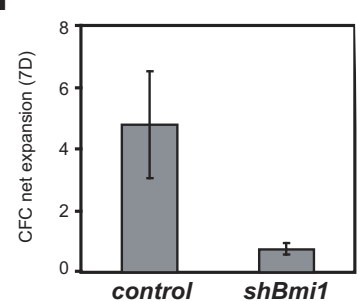

g

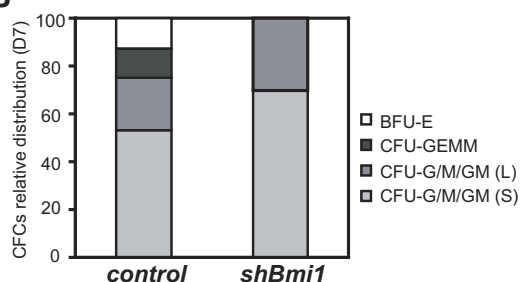

Retroviral

b

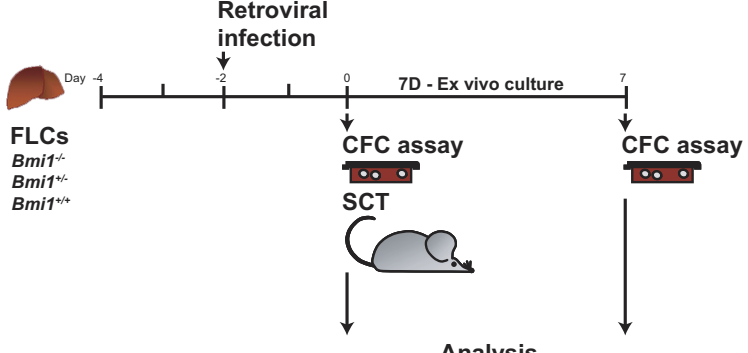

Analysis

h

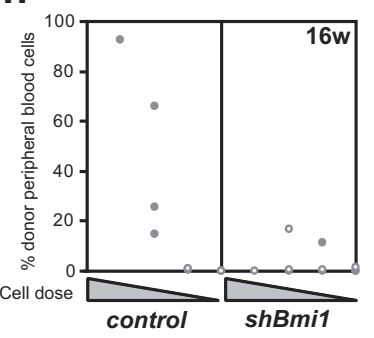

e

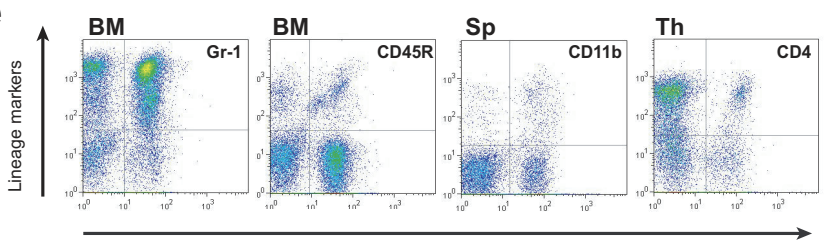

Donor cells

i

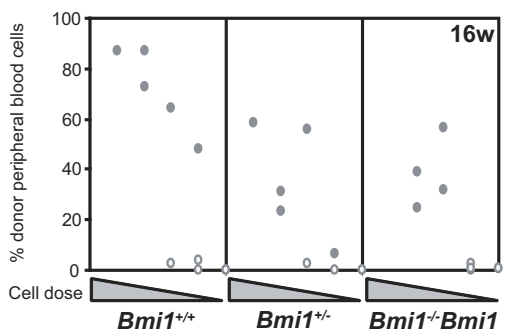

j

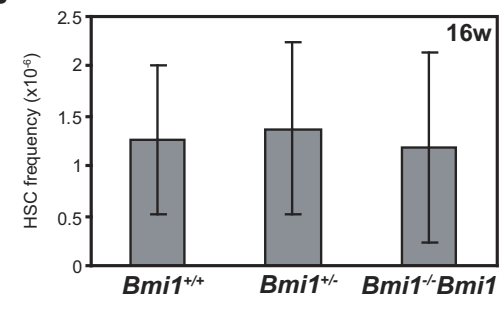

Figure 1. Bmil is required for hematopoietic stem cell function. (a) Retroviral constructs used in this study. (Sequences are available upon request to the author.) (b) Experimental outline. $\mathrm{Bmil}^{+/+}, \mathrm{Bmil}^{+/-}$, or $\mathrm{Bmil}^{-/-}$E14.5 fetal liver cells (FLCs) were transduced with a control, Bmil, or ShBmil retroviral vector. Stem cell transplantation (SCT) and colony-forming cell (CFC) assays were performed as described previously (Chagraoui et al. 2006). (c) CFC assays were performed 7 days postinfection $(n=60$ colonies analyzed per condition) (mean \pm S.D.). (d) Transduced Bmil ${ }^{-1-}$ FLCs $\left(3.3 \times 10^{6}\right.$ cells) were transplanted $(n=3$ mice per condition), and a proportion of donor-derived (Ly5.2 $2^{+}$) peripheral blood cells was assessed 12 weeks later (mean \pm S.D.). (e) Fluorescence-activated cell sorting (FACS) profiles of hematopoietic tissues from a representative Bmil ${ }^{-/}$Bmil chimeric mouse to determine myeloid (Gr-1, CD11b) and lymphoid (CD45R and CD4) reconstitution by donor cells $(n=3$ mice were analyzed). $(f)$ Expansion of CFCs during a series of 7-day ex vivo cultures (compared CFC numbers were determined at D0) (mean \pm S.D.). ( $g$ ) Relative distribution of CFC subtypes following a 7-day ex vivo culture. $(h)$ Donor-derived reconstitution of recipients of FLCs transduced with control versus shBmil virus, as indicated in $a$. Reconstitution was performed with a cell dose of $10^{7}$ (highest dilution) to 40,000 (lowest dilution) cells per mouse. $n=10$ mice per dilution. Each dot represents a mouse (solid vs. open dots: presence vs. absence of donor-derived lympho-myeloid reconstitution). Similar results were confirmed with bone marrow cells (BMCs) (data not shown). ( $i$ ) Transduced FLCs were transplanted ( $n$ $=10$ mice per condition) at limiting dilution (from $10^{6}$ to 20,000 cells) and peripheral blood cell reconstitution was assessed as in $h$. (j) HSC frequencies were evaluated using reconstitution results presented in $i$ (error bars indicate a $95 \%$ confidence interval). Results ( $i$ and $j$ ) were confirmed in two independent experiments. (BFU-E) Burst-forming-unit erythroid; (BM) bone marrow; (CFU-GEMM) colony-forming-unit granulocyte/erythroid/monocyte/megakaryocyte; (L) large (CFU-G/M/GM colonies with >50 cells); (S) small (CFU-G/M/GM colonies with $<50$ cells); (Sp) spleen; (Th) thymus. 
a

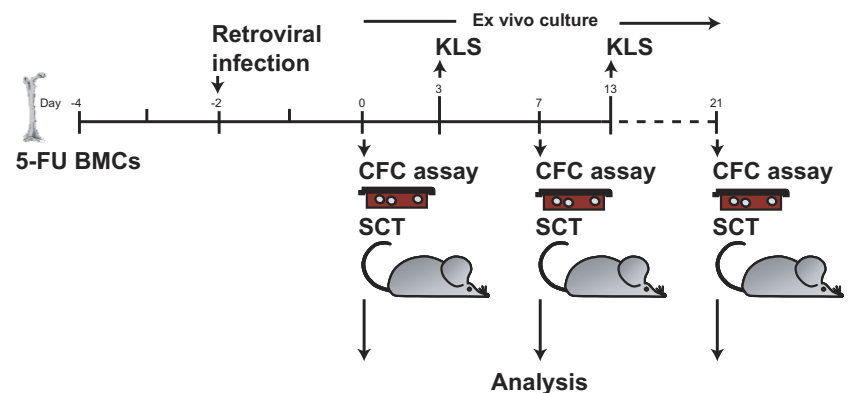

b

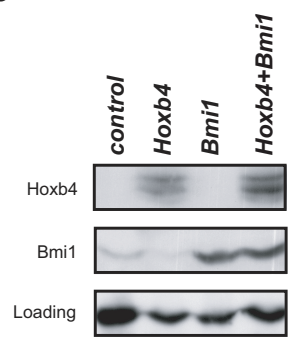

C

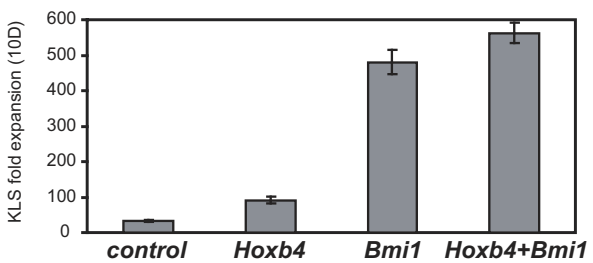

d

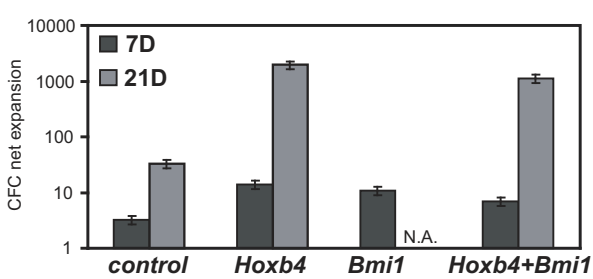

f

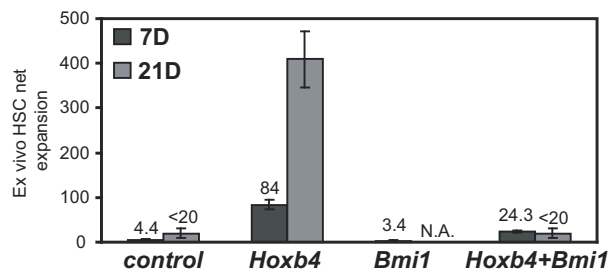

e
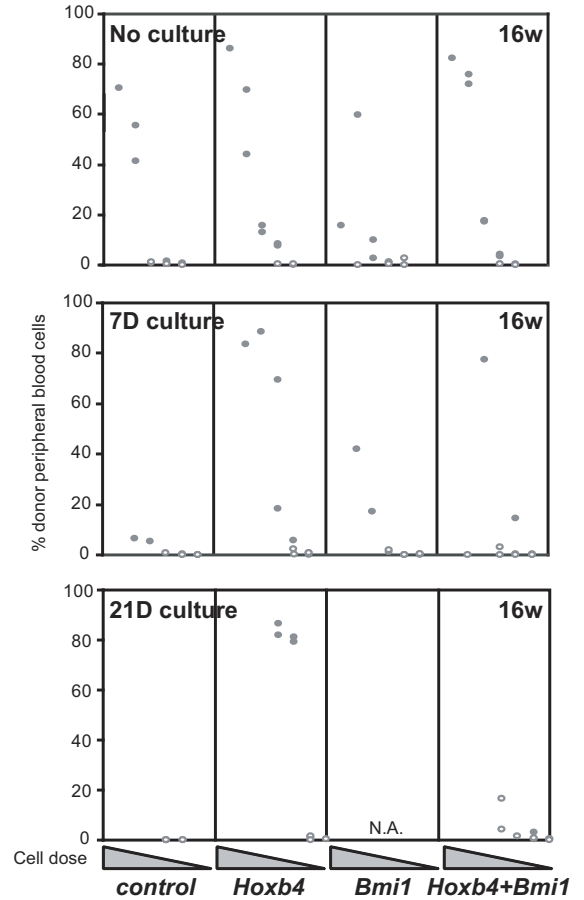

9

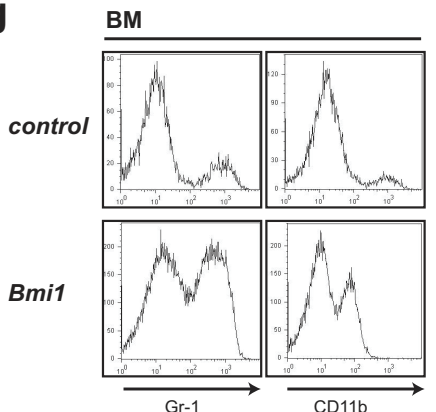

Sp
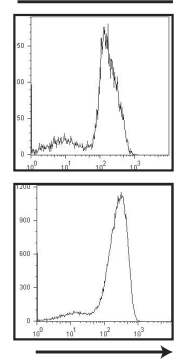

Th

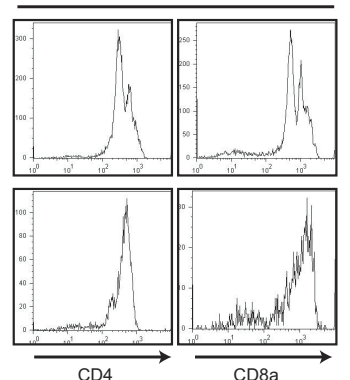

Figure 2. Bmil overexpression is not associated with ex vivo stem cell expansion. (a) Experimental outline. 5-Fluorouracil-treated bone marrow cells (5-FU BMCs) were transduced with control, Hoxb4, Bmil, or Hoxb4 + Bmil retroviral vectors. CFC $(n=50-100$ colonies analyzed per condition) and stem cell transplantation $(n=10$ mice per condition) assays were performed on days 0,7 , and 21 . (b) Western blot analysis of BMCs transduced with control, Hoxb4, Bmil, or Hoxb4 + Bmil retroviral vectors and immunoblotted with Hoxb4, Bmil, or ribosomal protein S6 (loading) antibodies. (c) Expansion of c-Kit ${ }^{+}$Lineage ${ }^{-}$Sca- $1^{+}$(KLS) cells during a 10-day culture period ( $n=3$ experiments) (mean \pm S.D.). (d) CFC expansion during 7 (black) or 21 days (gray) of ex vivo cultures (compared to $\mathrm{D} 0$ control CFC numbers) (mean \pm S.D.). (e) Transduced BMCs were transplanted at limiting dilution (from $10^{6}$ to 500 cells), and reconstitution was assessed 16 weeks later. (Upper, middle, lower panels) Experiments performed with cells isolated at days 0, 7, and 21 after initiation of the cultures, respectively (see also $a$ ). Cell dose for the experiments is represented in the upper panel: $10^{6}$ to 500 cells. (Middle, lower panels) All cultures were seeded with $10^{6}$ cells and recipients were transplanted with a range of 200,000 to 20 (D7) or 2,000 to 20 (D21) cells. Results for D0 and D7 were confirmed in three independent experiments and also with FLCs (data not shown). ( $f$ ) Seven-day (black) and 21-day (gray) ex vivo HSC expansions (in comparison to D0 control HSC numbers) were evaluated using reconstitution of recipients shown in $e(\geq 95 \%$ confidence interval). $(g)$ FACS profiles of hematopoietic tissues from selected recipients of GFP (control) versus Bmil-transduced cells from $f$. Abbreviations are the same as those in Fig. 1. 
expression conferred a small proliferative advantage to repopulating cells (i.e., higher reconstitution level per stem cell transplanted) (Fig. 2e, compare middle [Bmil] and first [control] panels).

\section{BMI1 IMPAIRS HOXB4-INDUCED HSC EXPANSION}

As shown in the previous sections, Bmil overexpression enhances proliferation of phenotypically primitive KLS hematopoietic cells, whereas Hoxb4 mostly triggers HSC self-renewal divisions. On the basis of these results, we inferred that these two genes may display potent genetic interaction leading to enhanced HSC expansion (e.g., enhanced proliferation [Bmil] of self-renewing [Hoxb4] HSCs). To verify this hypothesis, control, Hoxb4, and Hoxb4 + Bmil BMCs were kept in culture for up to 21 days and progenitor/stem cell contents were evaluated at various time points (Fig. 2a). As shown in Figure $2 \mathrm{~d}$, Hoxb4 progenitor activity was not enhanced by the engineered cooverexpression of Bmil after 7 or 21 days of culture. Importantly, expanded BMCs generated a large proportion of clones that expressed both Hoxb4 and Bmil, documenting the absence of negative interaction between these two genes in progenitors (data not shown).

In vivo reconstitution experiments performed with these same ex vivo expanded cells revealed that Hoxb4induced HSC expansion (e.g., 400-fold at 21 days; Fig. $2 \mathrm{f}$ ) is abrogated by the cooverexpression of Bmil (Fig. 2f). Importantly, the loss of HSC activity in cultures initiated with doubly transduced cells is not due to nonspecific toxicity of Bmil on HSC, because Hoxb4 + Bmil doubly transduced HSC are as competitive as Hoxb4 cells in vivo when transplanted immediately after gene transfer (Fig. 2e, upper panel). Thus, ex vivo, where the HSC-expanding activity of Hoxb4 is most prominent (Antonchuk et al. 2002), Bmil dominantly interferes with Hoxb4 activity while enhancing proliferation. As demonstrated using Annexin V staining, this effect was not consequential to a modulation of apoptosis, which was minimal in the KLS subfraction of all cultures analyzed (data not shown).

\section{$B_{M I}{ }^{-1}$ STR-HSC FUNCTION IS RESCUED BY Нохв4}

In an attempt to further investigate the genetic interaction between Hoxb4 and Bmil, experiments were performed to assess the possibility that Hoxb4 might complement the $B m i 1^{-/-}$progenitor and stem cell defects (Fig. 3a). As shown in Figure $3 \mathrm{~b}$ and c, $B m i 1^{-/}$progenitor numbers, differentiation potential, and proliferative activity are fully rescued by the engineered overexpression of Hoxb4.

In vivo experiments further revealed that Hoxb4 also complements the short-term hematopoietic reconstitution defects of $\mathrm{Bmil}^{-/}$cells to levels similar to those obtained for $\mathrm{Bmil}^{--} \mathrm{Bmil}$ cells (Fig. 3d, upper panel). Confirmation that reconstitution was derived from Hoxb4-transduced $\mathrm{Bmil}^{-/-}$cells was obtained by PCR-based analyses of peripheral blood samples isolated from several indepen- dent mice (Fig. 3d, middle [250-bp band] and lower panels) and from protein analysis of a representative specimen (Fig. 3e). Importantly, Bmi $1^{-/}$Hoxb4 cells were competent in myeloid $\left(\mathrm{Gr}-1^{+}\right)$, B lymphoid $\left(\mathrm{CD} 45 \mathrm{R}^{+}\right)$, and $\mathrm{T}$ lymphoid $\left(\mathrm{CD} \mathrm{a}^{+}\right)$differentiation in vivo (Fig. $\left.3 \mathrm{f}\right)$.

Interestingly, the reconstitution potential of $\mathrm{Bmil}^{-/-}$ Hoxb4 cells progressively decreased, such that by 12 weeks posttransplantation, it became almost undetectable (Fig. 3g). The rare donor-derived cells that persisted at 12 weeks in recipients of $\mathrm{Bmil}^{--}$Hoxb4 grafts were derived from myeloid $\left(\mathrm{CD} 11 \mathrm{~b}^{+}\right)$and lymphoid $\left(\mathrm{CD} 45 \mathrm{R}^{+}\right.$and $\mathrm{CD} 4{ }^{+} \mathrm{CD} 8 \mathrm{a}^{+}$) lineages (Fig. 3h). As might be expected from the results presented above, $B m i 1^{-/}$cells transduced with both Hoxb4 and Bmil persistently reconstituted all mice analyzed at 12 weeks post-SCT (Fig. 3g), and evaluation of the stem cell content in these grafts reveals that HSCs had expanded 20-35 times more than control HSCs (i.e., $\left.B m i 1^{-1-} B m i l\right)$ (data not shown). Together, these results suggest that $\mathrm{Bmil}^{-1-}$ FL-derived HSCs were complemented by Hoxb4 overexpression for reconstitution lasting up to $8-12$ weeks. However, Bmil is required to further sustain long-term stem cell activity (i.e., >12 weeks).

\section{HoXв4 TRIGGERS EXPANSION OF $B_{M I 1^{-1}}$ HSCS}

A series of additional experiments were conducted to further understand the nature of Hoxb4-induced rescue of $B m i 1^{-/}$repopulating cells. We specifically designed these experiments to determine whether Hoxb4 influenced the expansion (self-renewal) or the proliferative output of these $B m i 1^{-/}$cells (Fig. 4a). These experiments first showed that Hoxb4 overexpression induced a significant expansion of Lin $^{-} \mathrm{CD} 48^{-} \mathrm{CD} 150^{+}$populations in cultures initiated with $\mathrm{Bmil}^{-/-}$FLCs to levels similar to those determined in cultures initiated with wild-type cells (Fig. $4 \mathrm{~b}$ and data not shown). Furthermore, and consistent with results reported by Iwama et al. (2004), Lin $^{-} \mathrm{CD} 48^{-} \mathrm{CD} 150^{-}$wild-type and $B m i 1^{-/}$cells, lacking long-term reconstitution potential (Kiel et al. 2005; Kim et al. 2006), were poorly responsive to Hoxb4 overexpression (Fig. 4c).

The ex vivo expansion of Hoxb4-Bmi ${ }^{-/-}$repopulating cells was assessed at an early time point (i.e., 4 weeks) using the CRU assay as described originally (Szilvassy et al. 1990). Results from these experiments showed that Hoxb4 overexpression similarly triggered the net expansion of short-term repopulating (STR-HSC) cells from both genotypes $\left(\mathrm{Bmil}^{-/-}\right.$and $\left.\mathrm{Bmil}^{+/+}\right)$to values representing 2.5- to 3.9-fold, whereas untransduced STRHSCs decreased by approximately 10 -fold in these cultures (Fig. 4d). Thus, independent of Bmil genotype, cultures initiated with Hoxb4-transduced cells contained between 25 and 39 times more STR-HSCs than the control (Fig. 4d). Importantly, these cells maintained lymphoid and myeloid differentiation capacity but lacked the potential for long-term reconstitution (i.e., $>12$ weeks).

Confirmation of the lympho-myeloid potency of individual STR-HSCs was obtained for at least two clones where identical proviral integration profiles were identified in sorted myeloid $\left(\mathrm{Gr}-1^{+}\right)$and lymphoid $\left(\mathrm{CD} 45 \mathrm{R}^{+}\right)$ 

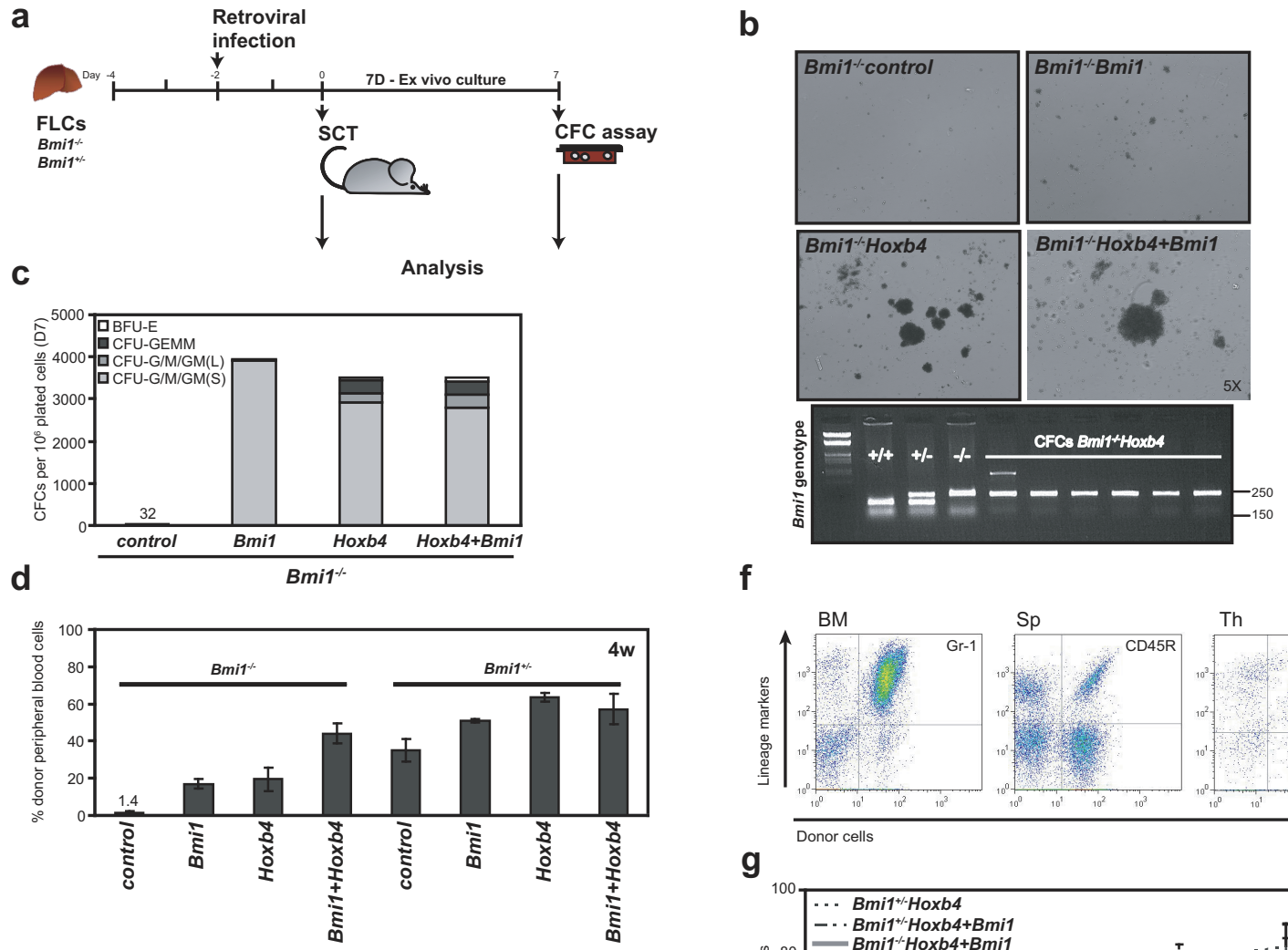

$\mathbf{f}$
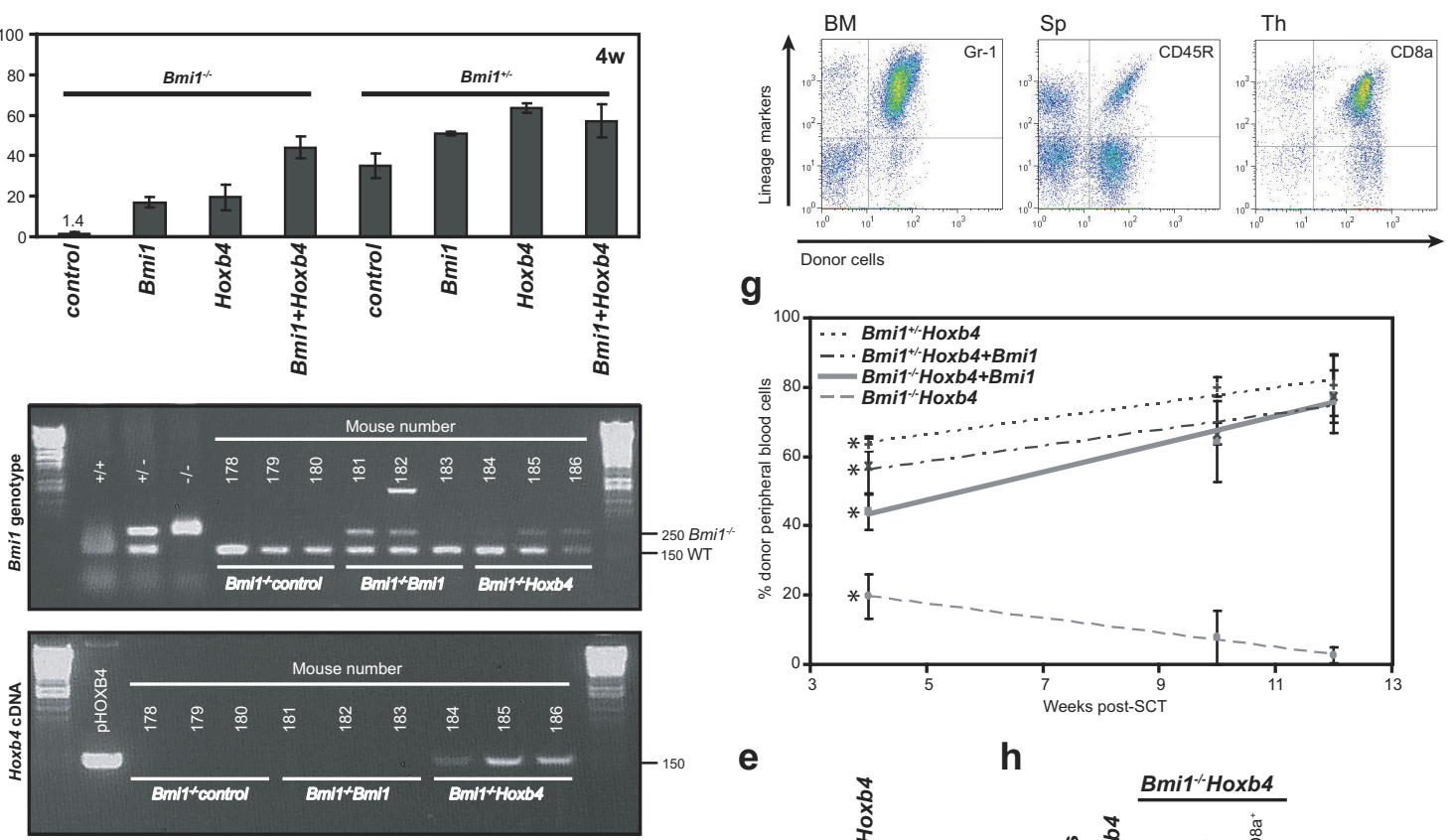

e

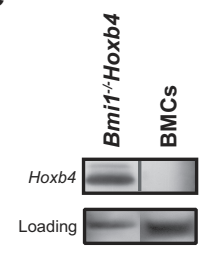

h

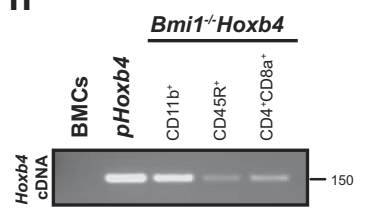

Figure 3. Hoxb4 overexpression rescues $\mathrm{Bmil}^{-/-}$STR-HSCs. (a) Experimental outline. $\mathrm{Bmil}^{-/-}$and $\mathrm{Bmil}^{+/-}$FLCs were transduced with control, Bmil, Hoxb4, or Hoxb4 + Bmil retroviral vectors. CFC and SCT assays were performed at the indicated time points. $(b, c)$ Transduced $\mathrm{Bmil}^{--}$FLCs were kept in culture for 7 days and plated in methylcellulose-containing medium for 7 days for CFC evaluation as described by Chagraoui et al. (2006). Pictures were taken at day 7 after initiation of the methylcellulose cultures $(n=60$ colonies analyzed per condition). (b, Lower panel) Genomic DNA was isolated from individual colonies picked from methylcellulose cultures initiated with Hoxb4-transduced Bmil $1^{--}$(or Bmi $1^{-/} H o x b 4$ ) cells and subjected to PCR analysis to confirm that Hoxb4-res-

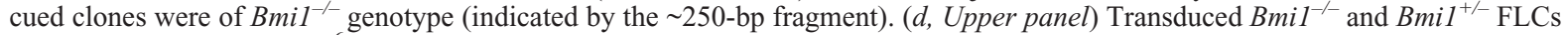
were transplanted $\left(3.3 \times 10^{6}\right.$ cells per mice, $\left.n=3\right)$, as indicated in $a$, and donor-derived reconstitution was evaluated 4 weeks later (mean \pm S.D.). (d, Middle panel) Same analysis as detailed in $b$ (lower panel) except that DNA was extracted from peripheral blood isolated from recipients 178-186 at 4 weeks posttransplantation. (d, Lower panel) Detection of Hoxb4 provirus by PCR in the same DNA. (e) Western blot analysis of protein extracts from sorted (Ly5.2+ $2^{+}$BMCs isolated from recipients of wild-type control or Bmi $1^{--} \mathrm{Hoxb}$ cells. Membranes were immunoblotted with antibodies that specifically recognize Hoxb4 or Tubulin $\beta$ (loading). $(f)$ Representative FACS profiles of hematopoietic tissues from a selected recipient of $B m i 1^{-1}$ Hoxb4-transduced cells. Analysis was performed using cells isolated at 4 weeks posttransplantation $(n=3$ mice analyzed). $(g)$ Time course showing donor-derived reconstitution (mean \pm S.D.) of several recipients of Bmil heterozygous or homozymous null FLCs transduced with the indicated retroviruses. (Asterisks) Results shown at 4 weeks are derived from $d$. $(h)$ The presence of Hoxb4-integrated provirus in the DNA of BMCs isolated from Bmi $1^{-/-} H o x b 4$ chimeric mice at 12 weeks posttransplantation. BMCs were sorted for myeloid $\left(\mathrm{CD} 11 \mathrm{~b}^{+}\right)$, B-lymphoid $\left(\mathrm{CD} 45 \mathrm{R}^{+}\right)$, and T-lymphoid $\left(\mathrm{CD}^{+} \mathrm{CD}^{2} \mathrm{a}^{+}\right)$populations, and amplification of the Hoxb4 provirus was performed by PCR $(n=3$ mice analyzed, one representative shown). Total BMCs were used as a negative control. Results were confirmed in three independent experiments. 
a

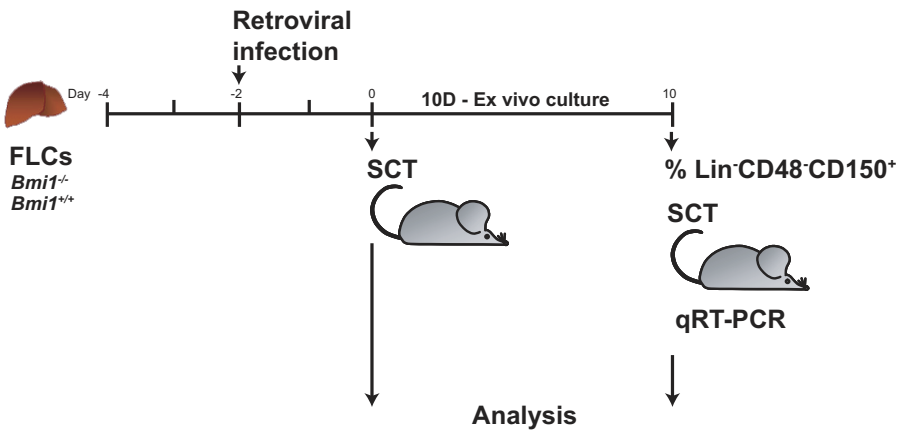

b
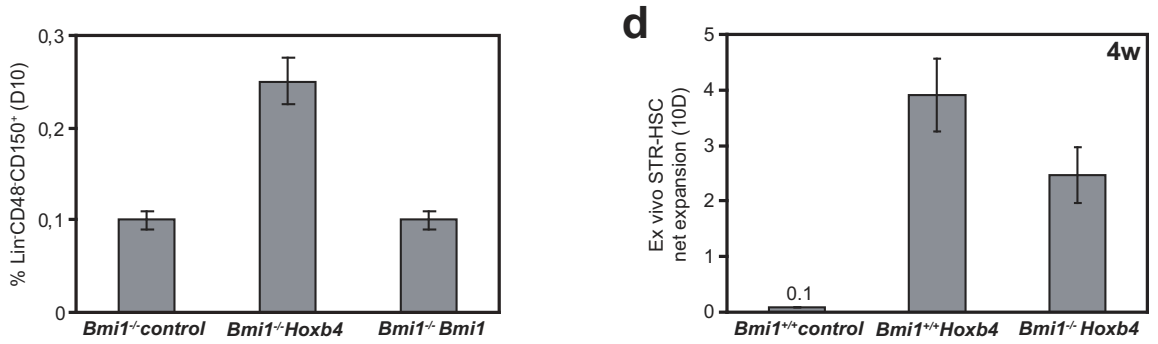

C

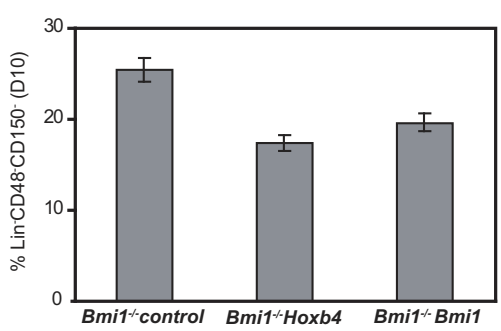

e

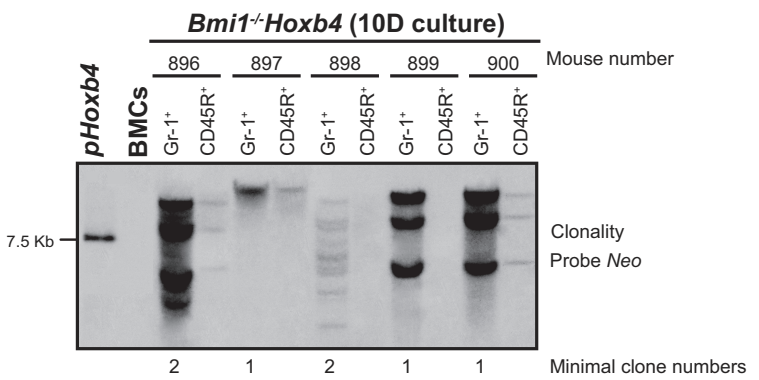

$\mathbf{f}$
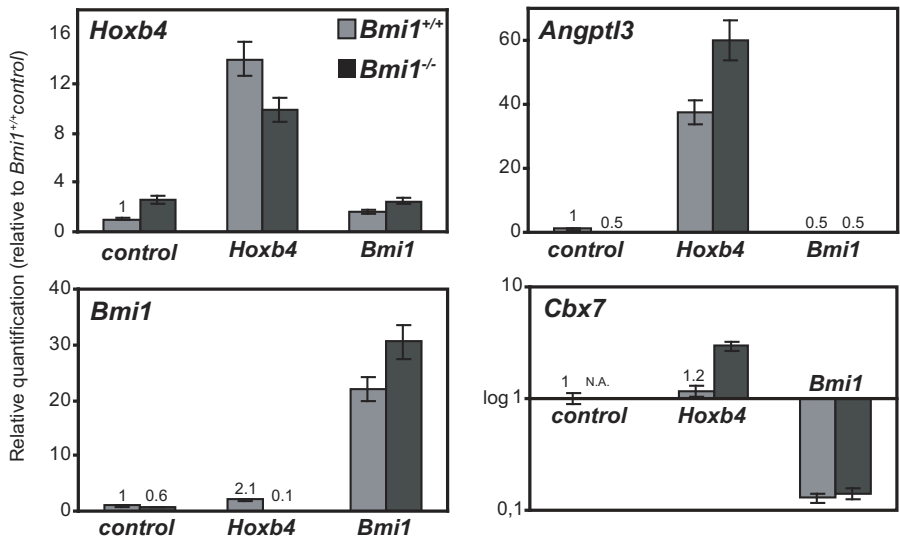

Figure 4. Hoxb4 induces expansion of STR-HSCs in the absence of Bmil. (a) Experimental outline. Bmil ${ }^{+/+}$and $\mathrm{Bmil}^{{ }^{-/}}$FLCs were transduced with control; Bmil or Hoxb4 retroviral vectors and cells were analyzed as indicated. $(b, c)$ Proportion of $\mathrm{Lin}^{-} \mathrm{CD} 48^{-} \mathrm{CD} 150^{+}$ and of $\mathrm{Lin}^{-} \mathrm{CD} 48^{-} \mathrm{CD} 150^{-}$cells in cultures initiated with the indicated cell populations. FACS analyses were performed 10 days after the cultures were initiated (mean \pm S.D.). (d) Determination of STR-HSC net expansion during a 10-day culture as described in $a-c$. STRHSC determination was performed using the CRU assay with a minimum of ten recipients per dilution. Assessment of donor-derived reconstitution was performed at 4 weeks posttransplantation, hence the definition of STR-HSC in these experiments (error bar indicates a 95\% confidence interval). (e) Southern blot analysis of genomic DNA isolated from Hoxb4-transduced Bmil ${ }^{-/-}$BMCs and sorted based on the expression of $\mathrm{Gr}_{-1}^{+}$(myeloid) or CD45R $\mathrm{R}^{+}$(B-lymphoid) surface markers. Note that cells were collected at 4 weeks and 9 weeks posttransplantation for mouse 896 and mice 897-900, respectively. The DNA was digested with EcoRI, which cuts once in the integrated proviruses, and membranes were probed with a radiolabeled neomycin resistance gene fragment. Each fragment documents a unique insertion site for the Hoxb4 provirus in the sorted populations. (f) Q-RT-PCR analyses of Hoxb4 (left upper panel), Bmil (left lower panel), Angptl3 (right upper panel), and Cbx7 (right lower panel) expression in sorted $\mathrm{Lin}^{-\mathrm{CD}} 48^{-} \mathrm{CD} 150^{+} \mathrm{Bmil}^{+/+}$and $\mathrm{Bmil}{ }^{-/-}$ cells engineered to overexpress GFP (control) or Hoxb4-GFP or Bmil-GFP. Results are presented as levels relative to those derived from $G F P$-transduced $\mathrm{Bmil}^{+/+}$cells. Quality of RNA was evaluated using Gapdh primer sets. Primer sequences available upon request. 
populations isolated from selected recipients 9 weeks post-SCT (Fig. 4e, mice 897 and 900). Further analysis of proviral integrations in bone-marrow-derived cells from these recipients revealed that at least six Hoxb4-transduced clones contributed to repopulation (see minimal clone numbers indicated at the bottom of Fig. 4e).

Most importantly, recipients 899 and 900 were repopulated by identical retrovirally marked clones, a typical signature for SR that occurred during the 10-day culture period before transplantation (Fig. 4e). The $\mathrm{Bmil}^{-1-}$ cell type (HSC vs. progenitor) that underwent SR as a result of Hoxb4 overexpression is undefined. However, three arguments suggest that this cell type was an HSC. First, Hoxb4 overexpression fails to recruit non-HSCs (progenitors) into this compartment (Park et al. 2003; Iwama et al. 2004). Second, the results presented in Figure $1 \mathrm{i}$ and $\mathrm{j}$ indicate that LTR-HSCs are present in normal numbers in $B m i 1^{-1}$ fetal livers. Third, complementation experiments summarized in Figure $1 \mathrm{j}$ indicate that $\mathrm{Bmil}^{-/-}$LTR-HSCs can expand normally in vivo during embryonic development.

\section{DIFFERENT PATHWAYS ARE REGULATED BY BMI1 AND Нохв4}

The different impact of Hoxb4 and Bmil on HSC activity suggests that they affect distinct gene subsets. To gain insight into this possibility, we performed Q-RT-PCR studies on sorted $\mathrm{Lin}^{-} \mathrm{CD} 48^{-} \mathrm{CD} 150^{+}$cells engineered to overexpress Hoxb4 or Bmil and compared the expression of approximately 110 candidate gene targets in these cells. These genes included Hox members and cofactors, Polycomb group genes, and other stem cell regulators such as Etv6 (Wang et al. 1998), Gfil (Hock et al. 2004; Zeng et al. 2004), and Lnk (Ema et al. 2005). The expression of most of these genes was unaffected by Hoxb4 or Bmil (Table 1). However, we found that Angptl3 (but not Angptl2) expression was strongly induced by Hoxb4 in HSC-enriched cells and that this regulation was observed in wild-type and $\mathrm{Bmil}^{-/}$cells (Fig. 4f). Conversely, the Polycomb group gene $C b x 7$ is down-regulated by Bmil and not by Hoxb4 (Fig. 4f).

\section{BMI1 INTEGRATES MULTIPLE PATHWAYS IN THE REGULATION OF HSC ACTIVITY}

Hoxb4-induced complementation of $\mathrm{Bmil}^{-/-}$repopulating cells is reminiscent of that recently described by our group for the loss of function of E4F1 (Chagraoui et al. 2006) and by other groups for arf/ink $4 a$ and p53 (Jacobs et al. 1999; Bruggeman et al. 2005; Molofsky et al. 2006; Oguro et al. 2006; Akala et al. 2008). In fact, besides the recent results with p53 (Akala et al. 2008), it remains challenging to identify a single gene whose gain or loss of function can fully rescue $B m i 1^{--}$LTR-HSC activity. The recent identification of the $\operatorname{arf} /$ ink $4 a$ locus as a direct target for Bmil, together with its direct interaction with E4F1, may suggest that both pathways are simultaneously regulated in self-renewing HSCs. Furthermore, the essential role for Bmil as a cofactor to Ring1/2 ubiquitin E3 ligase in possibly promoting monoubiquitination of H2A (K119) suggests that other regulators may be involved (Fig. 5a).

\section{CONCLUSIONS}

Because HSC expansion occurs strictly as a result of symmetrical self-renewal divisions, we conclude that Bmil is not essential for this function (at least before E14.5 in vivo and likely as a result of Hoxb4 overexpression in vitro). This provides evidence to propose that execution and sustainability of SR are independently regulated in HSCs and that although the first appears to be regulated by Hox genes and their targets, the former is under the control of Bmil (Fig. 5b). On the basis of this, it is tempting to speculate that in the absence of Bmil, LTR-HSCs become functionally equivalent to STRHSCs.

Table 1. Genes not regulated by Hoxb4 and Bmil overexpression in $\mathrm{Lin}^{-} \mathrm{CD} 48^{-} \mathrm{CD} 150^{+}$cells

\begin{tabular}{|c|c|c|c|c|}
\hline Acin1 & Egrl & Hoxa9 & Nfat 5 & Rnf2 \\
\hline Angpti2 & Epc2 & Hoxbl & Notch1 & Runxl \\
\hline Asxl1 & Etv6 & Hoxb13 & Numb & Runx2 \\
\hline Asxl2 & Exh1 & Hoxb2 & Pard3 & Scmh1 \\
\hline Atf4 & Ezh2 & Hoxb3 & Pard6a & Scml2 \\
\hline Bazlb & Foxo3a & Hoxb5 & Pard6b & $S f 1$ \\
\hline Вmp2 & Gata2 & Hoxb6 & Pcgf2 (Mel18) & Sfpil (Pu.1) \\
\hline Bmp4 & Gfil & Hoxb7 & Pcgf6 & Sh2b3 (Lnk) \\
\hline Втр7 7 & Gli1 & Hoxb8 & Phcl (Rae-28) & Smarccl \\
\hline Bteb1 & Gli2 & Hoxb9 & $P h c 2$ & Stat3 \\
\hline Casp8ap2 & Gli3 & $\operatorname{Irx} 5$ & $P h c 3$ & Stat $5 a$ \\
\hline$C b f b$ & $H 3 f 3 b$ & L3mbtil & Phfl & Suz12 \\
\hline$C b \times 2$ & Hoxal & L3mbti2 & Pknoxl (Prep1) & Tall \\
\hline Cbx 4 & Hoxa10 & L3mbti3 & Pknox2 (Prep2) & $T c f 4$ \\
\hline Cbx6 & Hoxal1 & Lef1 & $\operatorname{Prdm} 16$ & $T c f e 2 a(E 2 a)$ \\
\hline Cbx 8 & Hoxa13 & Lmo2 & Proxl & Tgif \\
\hline Cebpa & Hoxa2 & $\operatorname{Mef} 2 c$ & Pten & Trim 2 \\
\hline Crebbp & Ноха 3 & Meis1 & Rapla & $\operatorname{Trim} 28$ \\
\hline Crem & Hoxa4 & Mrg1 (Meis2) & Rarb & $X b p 1$ \\
\hline Dnmt3b & Hoxa 5 & Mrg2 (Meis3) & Rela & \\
\hline Eed & Hoxa6 & $M y b$ & Rest & \\
\hline Egfr & Ноха7 & $\mathrm{Ncl}$ & ring1 & \\
\hline
\end{tabular}


a
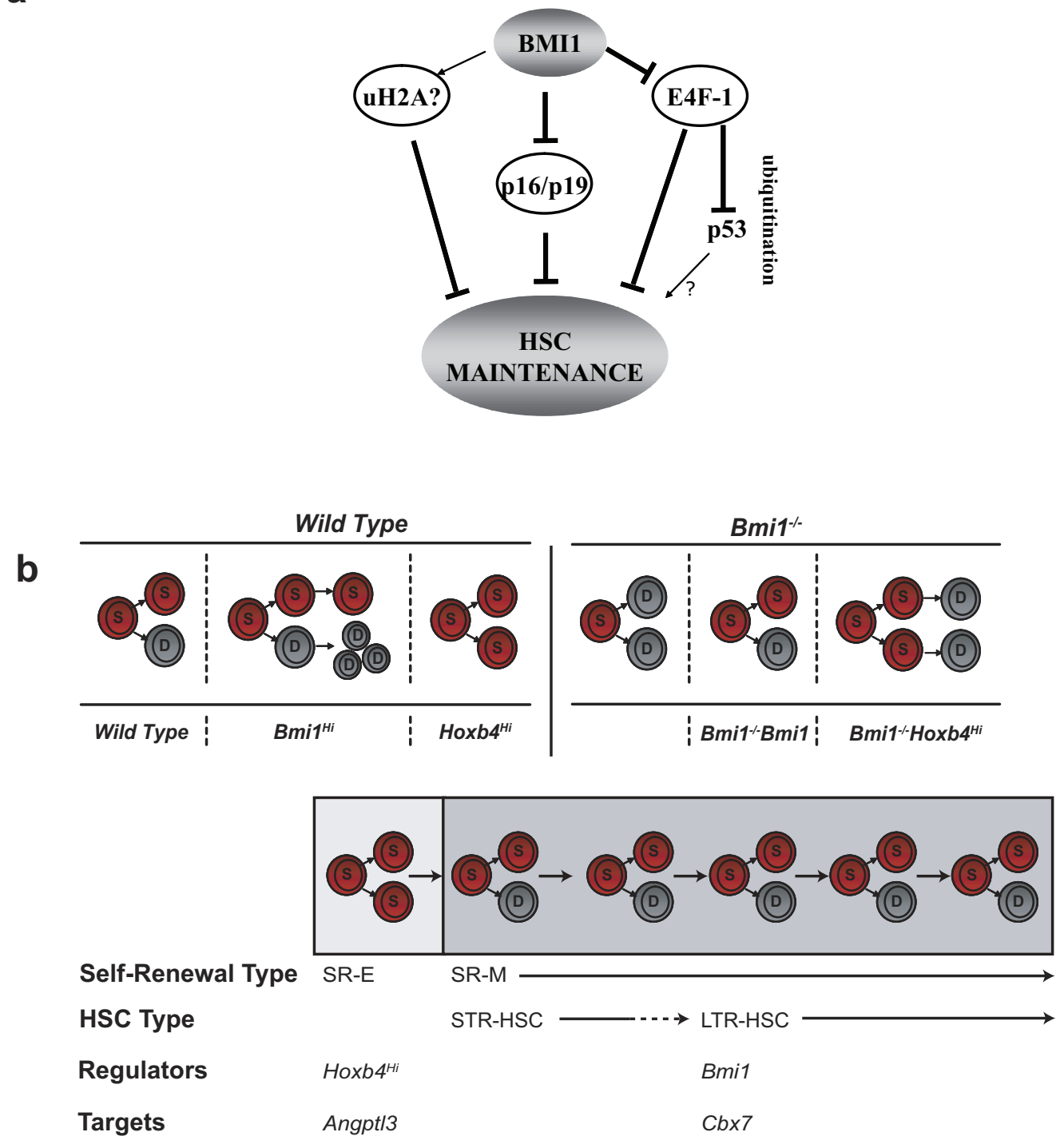

Figure 5. Complementary and independent function for Hoxb4 and Bmil in HSC activity.

\section{ACKNOWLEDGMENTS}

We thank Edlie St. Hilaire for her technical help regarding mouse manipulation and to Jana Krosl for critical reviews of this paper. We express our gratitude to Sonia Cellot, Simon Girard, Jana Krosl, and Martin Sauvageau for their good advice and to Christian Charbonneau, Danièle Gagné, and Pierre Chagnon for their help with the imaging, flow cytometry, and genomic core facilities of IRIC, respectively. This work was financed by the Canadian Institutes of Health Research and the National Institutes of Health. A.F. was a Fond de la Recherche en Santé du Québec (FRSQ) and National Cancer Institute of Canada (NCIC)/Terry Fox Foundation Studentships recipient. G.S. holds a Canada Research Chair in Molecular Genetics of Stem Cells.

\section{REFERENCES}

Akala, O.O., Park, I.K., Qian, D., Pihalja, M., Becker, M.W., and Clarke, M.F. 2008. Long-term haematopoietic reconstitution by $\operatorname{Trp} 53^{-/} p 16 \operatorname{Ink} 4 a^{-/} p 19 \mathrm{Arf}^{--}$multipotent progenitors. Nature 453: 228-232.

Antonchuk, J., Sauvageau, G., and Humphries, R.K. 2001. HOXB4 overexpression mediates very rapid stem cell regeneration and competitive hematopoietic repopulation. Exp. Hematol. 29: 1125-1134.

Antonchuk, J., Sauvageau, G., and Humphries, R.K. 2002. HOXB4-induced expansion of adult hematopoietic stem cells ex vivo. Cell 109: 39-45.

Bruggeman, S.W., Valk-Lingbeek, M.E., van der Stoop, P.P., Jacobs, J.J., Kieboom, K., Tanger, E., Hulsman, D., Leung, C., Arsenijevic, Y., Marino, S., and van Lohuizen, M. 2005. Ink4a and $A r f$ differentially affect cell proliferation and neural stem cell self-renewal in Bmil-deficient mice. Genes Dev. 19: 1438-1443.

Cellot, S., Krosl, J., Chagraoui, J., Meloche, S., Humphries, R.K., and Sauvageau, G. 2007. Sustained in vitro trigger of self-renewal divisions in Hoxb4hiPbx1(10) hematopoietic stem cells. Exp. Hematol. 35: 802-816.

Chagraoui, J., Niessen, S.L., Lessard, J., Girard, S., Coulombe, P., Sauvageau, M., Meloche, S., and Sauvageau, G. 2006. E4F1: A novel candidate factor for mediating BMI1 function in primitive hematopoietic cells. Genes Dev. 20: $2110-2120$. Christensen, J.L. and Weissman, I.L. 2001. Flk-2 is a marker in 
hematopoietic stem cell differentiation: A simple method to isolate long-term stem cells. Proc. Natl. Acad. Sci. 98: $14541-$ 14546.

Dykstra, B., Kent, D., Bowie, M., McCaffrey, L., Hamilton, M., Lyons, K., Lee, S.J., Brinkman, R., and Eaves, C. 2007. Longterm propagation of distinct hematopoietic differentiation programs in vivo. Cell Stem Cell 1: 218-229.

Ema, H., Sudo, K., Seita, J., Matsubara, A., Morita, Y., Osawa, M., Takatsu, K., Takaki, S., and Nakauchi, H. 2005. Quantification of self-renewal capacity in single hematopoietic stem cells from normal and Lnk-deficient mice. Dev. Cell 8: 907-914.

Hock, H., Hamblen, M.J., Rooke, H.M., Schindler, J.W., Saleque, S., Fujiwara, Y., and Orkin, S.H. 2004. Gfi-1 restricts proliferation and preserves functional integrity of haematopoietic stem cells. Nature 431: 1002-1007.

Iwama, A., Oguro, H., Negishi, M., Kato, Y., Morita, Y., Tsukui, H., Ema, H., Kamijo, T., Katoh-Fukui, Y., Koseki, H., van Lohuizen, M., and Nakauchi, H. 2004. Enhanced self-renewal of hematopoietic stem cells mediated by the Polycomb gene product Bmi-1. Immunity 21: 843-851.

Jacobs, J.J.L., Kieboom, K., Marino, S., DePinho, R.A., and van Lohuizen, M. 1999. The oncogene and Polycomb-group gene bmi-1 regulates cell proliferation and senescence through the ink4a locus. Nature 397: 164-168.

Kiel, M.J., Yilmaz, O.H., Iwashita, T., Yilmaz, O.H., Terhorst, C., and Morrison, S.J. 2005. SLAM family receptors distinguish hematopoietic stem and progenitor cells and reveal endothelial niches for stem cells. Cell 121: 1109-1121.

Kim, I., He, S., Yilmaz, O.H., Kiel, M.J., and Morrison, S.J. 2006. Enhanced purification of fetal liver hematopoietic stem cells using SLAM family receptors. Blood 108: 737-744.

Krosl, J., Austin, P., Beslu, N., Kroon, E., Humphries, R.K., and Sauvageau, G. 2003. In vitro expansion of hematopoietic stem cells by recombinant TAT-HOXB4 protein. Nat. Med. 9: 14281432.

Lessard, J. and Sauvageau, G. 2003. Bmi-1 determines the proliferative capacity of normal and leukaemic stem cells. Nature 423: $255-260$.

Molofsky, A.V., Slutsky, S.G., Joseph, N.M., He, S., Pardal, R., Krishnamurthy, J., Sharpless, N.E., and Morrison, S.J. 2006. Increasing $\mathrm{p} 16^{I N K 4 a}$ expression decreases forebrain progenitors and neurogenesis during ageing. Nature 443: 448-452.

Morrison, S.J., Wandycz, A.M., Hemmati, H.D., Wright, D.E., and Weissman, I.L. 1997. Identification of a lineage of multipotent hematopoietic progenitors. Development 124: 1929-1939.

Oguro, H., Iwama, A., Morita, Y., Kamijo, T., van Lohuizen, M., and Nakauchi, H. 2006. Differential impact of Ink4a and Arf on hematopoietic stem cells and their bone marrow microenvironment in Bmil-deficient mice. J. Exp. Med. 203: $2247-2253$.
Ohta, H., Sekulovic, S., Bakovic, S., Eaves, C.J., Pineault, N., Gasparetto, M., Smith, C., Sauvageau, G., and Humphries, R.K. 2007. Near-maximal expansions of hematopoietic stem cells in culture using NUP98-HOX fusions. Exp. Hematol. 35: $817-830$.

Park, I.K., Qian, D., Kiel, M., Becker, M.W., Pihalja, M., Weissman, I.L., Morrison, S.J., and Clarke, M.F. 2003. Bmi1 is required for maintenance of adult self-renewing haematopoietic stem cells. Nature 423: 302-305.

Pawliuk, R., Eaves, C., and Humphries, R.K. 1996. Evidence of both ontogeny and transplant dose-regulated expansion of hematopoietic stem cells in vivo. Blood 88: 2852-2858.

Rebel, V.I., Miller, C.L., Thornbury, G.R., Dragowska, W.H., Eaves, C.J., and Lansdorp, P.M. 1996. A comparison of longterm repopulating hematopoietic stem cells in fetal liver and adult bone marrow from the mouse. Exp. Hematol. 24: 638648.

Sauvageau, G., Thorsteinsdottir, U., Eaves, C.J., Lawrence, H.J., Largman, C., Lansdorp, P.M., and Humphries, R.K. 1995. Overexpression of $H O X B 4$ in hematopoietic cells causes the selective expansion of more primitive populations in vitro and in vivo. Genes Dev. 9: 1753-1765.

Shen, Q., Zhong, W., Jan, Y.N., and Temple, S. 2002. Asymmetric Numb distribution is critical for asymmetric cell division of mouse cerebral cortical stem cells and neuroblasts. Development 129: 4843-4853.

Szilvassy, S.J., Humphries, R.K., Lansdorp, P.M., Eaves, A.C., and Eaves, C.J. 1990. Quantitative assay for totipotent reconstituting hematopoietic stem cells by a competitive repopulation strategy. Proc. Natl. Acad. Sci. 87: 8736-8740.

Thorsteinsdottir, U., Sauvageau, G., and Humphries, R.K. 1999. Enhanced in vivo regenerative potential of HOXB4-transduced hematopoietic stem cells with regulation of their pool size. Blood 94: 2605-2612.

Thorsteinsdottir, U., Mamo, A., Kroon, E., Jerome, L., Bijl, J., Lawrence, H.J., Humphries, R.K., and Sauvageau, G. 2002. Overexpression of the myeloid leukemia-associated Hoxa 9 gene in bone marrow cells induces stem cell expansion. Blood 99: $121-129$.

Wang, L.C., Swat, W., Fujiwara, Y., Davidson, L., Visvader, J., Kuo, F., Alt, F.W., Gilliland, D.G., Golub, T.R., and Orkin, S.H. 1998. The TEL/ETV6 gene is required specifically for hematopoiesis in the bone marrow. Genes Dev. 12: 2392-2402.

Wognum, A.W., Eaves, A.C., and Thomas, T.E. 2003. Identification and isolation of hematopoietic stem cells. Arch. Med. Res. 34: 461-475.

Zeng, H., Yücel, R., Kosan, C., Klein-Hitpass, L., and Möröy, T. 2004. Transcription factor Gfil regulates self-renewal and engraftment of hematopoietic stem cells. EMBO J. 23: 41164125 . 


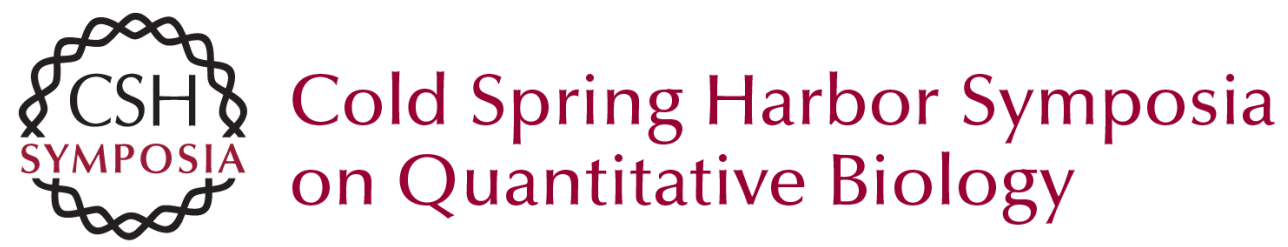

\section{Complementary and Independent Function for Hoxb4 and Bmi1 in HSC Activity}

A. Faubert, J. Chagraoui, N. Mayotte, et al.

Cold Spring Harb Symp Quant Biol 2008 73: 555-564 originally published online November 6, 2008 Access the most recent version at doi:10.1101/sqb.2008.73.030

References This article cites 31 articles, 13 of which can be accessed free at: http://symposium.cshlp.org/content/73/555.full.html\#ref-list-1

\section{License}

Email Alerting Receive free email alerts when new articles cite this article - sign up in the box at the Service top right corner of the article or click here. 